\title{
WASTE RECYCLING IN MALAYSIA: TRANSITION FROM DEVELOPING TO DEVELOPED COUNTRY
}

\section{Innocent A. Jereme}

PhD Candidate, Institute for Environment and Development (LESTARI)

National University of Malaysia (UKM), Malaysia

E-mail: innoviva2001@yahoo.com

\author{
Chamhuri Siwar \\ Emeritus Professor \\ Institute for Environment and Development (LESTARI) \\ National University of Malaysia (UKM), Malaysia \\ E-mail: csiwar@ukm.my
}

Md. MahmudulAlam

PhD Student, Institute for Environment and Development (LESTARI)

National University of Malaysia (UKM), Malaysia

E-mail: rony000@gmail.com

\section{Citation Reference:}

Jereme, I.A., Alam, M.M. and Siwar, C. 2015. Waste Recycling in Malaysia: Transition from Developing to Developed Country, Indian Journal of Education and Information Management. Vol. 4 (1), pp. 1-14. (online) http://ijeim.informaticspublishing.com/index.php/ijeim/article/viewFile/80238/62033

This is a pre-publication copy.

The published article is copyrighted by the publisher of the journal. 


\title{
WASTE RECYCLING IN MALAYSIA: TRANSITION FROM DEVELOPING TO DEVELOPED COUNTRY
}

\begin{abstract}
The issue of sustainable waste management has become an important priority for policymakers and other relevant stakeholders of Malaysia as the country prepares to project itself as a developed nation. Despite several attempts by the government, such as enactment of new laws and pursuing privatisation, Malaysia is still lagging behind significantly in sustainable waste management practices, particularly in the area of recycling. Based on studies conducted in the Selangor state of Malaysia, this paper attempts to analyse the current waste management practices of Malaysia along with their problems and prospects, and examine the steps taken by the government and other stakeholders for attaining sustaining waste management practices. The paper will help the policy makers, waste management strategists, local administrators and researchers in the field to formulate sustainable policies and identify further areas of study in the relevant field.
\end{abstract}

Keywords: Waste management, recycling, solid waste, informal sector

\section{INTRODUCTION}

The issue of waste disposal management has recently gained widespread attention in virtually all states of Malaysia. With the communities facing rapidly increasing disposal costs, the opinion leaders denouncing the amount of materials being thrown away as environmentally and ethically unsound, the lawmakers struggling for sustainable solutions - pressure is mounting on manufactures and packagers of consumer goods to minimise the amount of refuse. Amidst these changing circumstances, some laws have recently been passed making waste management a national issue in Malaysia and many others have similar laws on their agenda (Yahaya 2007a).

Hand in hand with the high rate of economic growth in the past few decades, the population of Malaysia have grown from 21,793293 in 2000 to 28,339273 in 2010/11. Considering these economic and population growths together, Malaysia is generating more wastes now in comparison to any previous point of time in history. It is estimated that about 18,000 tons of wastes are generated in Malaysia per day and this figure is expected to increase at the rate of $2 \%$ every year. Out of these, $75 \%$ of the wastes generated are collected and disposed at dumpsites or landfills that are not sanitary. In Kuala Lumpur, only 5\% of the wastes generated in the city are recycled and the rest goes to landfills (Yassin 2006).

As of April 2007, there were 291 landfill sites in Malaysia to dump wastes, out of which only ten were sanitary landfills; of these 291 sites, 112 were closed and the remaining 179 were still in operation. It is expected that solid waste generation in Malaysia will reach 30,000 tons per day in 2020 (Yahaya 2007a). A waste reduction study conducted by the Local Government Authority indicates that food waste and other organic waste constitute $47 \%$ of the total wastes generated, followed by paper $15 \%$, plastics $14 \%$, and others constitute the rest (Yassin 2006). In 2020, there is target to recycle 20\% of the total wastes generated, $15 \%$ for intermediate processing and the remaining $65 \%$ to be deposited at various landfill sites. Besides, the existing legislations on waste management were reviewed to 
improve solid waste management by privatizing it and to increase recycling awareness in the country (MHLG 2003).

This alarming situation in waste disposal management prompted the Malaysian Government to launch the $6^{\text {th }}$ Malaysia Plan (MP) for 1991-1995, with an emphasis on diversifying the sources of growth of the wastes. The $7^{\text {th }}$ Malaysia Plan (MP) for 1996-2000 also focused on the quality of life and the environment. As the population continued to grow and available lands were becoming scarce for acquiring landfill sites due to opposition by residents and community leaders, in the $8^{\text {th }}$ Malaysia Plan (MP) for 2001-2005, a National Recycling Program was re-launched with these objectives as follows:
a. Inculcate the habit of recycling among the population;
b. Reduce operational cost of solid waste management;
c. Minimize the volumes of waste disposal by landfills;
d. Reduce utilization of raw materials; and
e. Improve awareness and cooperation among stakeholders (MHLG 2003).

Under the $9^{\text {th }}-10$ th Malaysia Plans and with the implementation of the Solid Waste Management Bill, the recycling and disposal of solid waste will be privatised in order to improve services, relinquish the financial burden and include the private sector. These concessionaries are responsible for collection, storage, transportation, treatment and recycling of all of the country's non-hazardous wastes (Market Watch 2011).

Recycling on the other hand means to compost and regenerate materials for original purpose or for other purposes (Lewis and Hall 1990). Recycling should be seen therefore as the means by which we seek to minimize the environmental impact of both raw material production and waste disposal. The popular meaning of recycling in most developed countries has come to the widespread collections and reuse of various items such as newspapers and drinks bottles. They are collected and sorted out into common types so that the raw materials from it could these items can be used again to create new products. Therefore this study explores to understand the waste management in Malaysia and how it linked with the transition from developing to developed country.

\section{WASTE RECYCLING IN MALAYSIA}

Malaysia started the privatization of waste management operation in 1994 (Budzik et al. 2002). Gradually waste collection and public space cleansing service are being taken over by Alam Flora Sdn Bhd. To smooth the process, the consortia were instructed to take over the solid waste management over an interim period. The full-flash privatization is still to be determined by the government pending legislation based on the new National Waste Bill. Until the privatization is fully implemented, most aspects of solid waste management will be continued to be in the realm of Local Government.

Although the current large-scale privatization entails a more comprehensive transfer of activities and function than the previous semi-privatization measures, the public sector cannot pass all responsibilities onto the private sector. Since the waste management privatization was initiated on national level, the Federal Government will be responsible for ensuring that the consortia conform to the standards, and rules and legislation as required by the Government. This is done via the Department of Local Government at the Ministry of Housing and Local Government (MHLG) while the Department of Environment (DOE) its responsibilities lie mainly in general pollution control and Environmental Impact Assessment 
(EIA) of waste treatment facilities (Hassan 2002). The federal government has now taken over management of solid waste with the creation of the National Solid waste Department and the bill was signed into law this 2011 .

The actual operationalization of the MHLG's responsibilities lie significantly with the local authorities, who will remain central in terms of enforcing laws and regulations and ensuring that private sector meets required standard and quality (MHLG 2003). As part of the privatization process, the fees for the waste management services are now no longer the responsibility of the local authorities but must be managed by the waste management company. The particulars of this financial aspect of the waste services have not yet been addressed, but as the fee is not planned to be included in the semi-annual assessment rates imposed by the local authorities, a separate fee must be introduced. The introduction of such a fee meets some political and public opposition in Malaysia (Hassan 2002). The fees have not been settled till date between the private companies with the government as it has some political undertone because the public don't want to pay for perceive unseen service.

The interim period status of the solid waste service provision has resulted in uncertainty by both the concessionaires and the Local Authority's especially the wait for the imminent National Waste Bill and the issues of service fees are creating some implications in regards to further development and final realization of the privatization process. It can be argued that these uncertainties pertain to a reluctance to invest in new resources and equipment by various stakeholders has resulted in relative short-term planning.

\subsection{Waste collection and transport}

Waste collection in Selangor is managed by the Alam Flora Sdn, though they employ private collection companies to deal with the actual waste collection. In the waste concession area of Alam Flora Sdn Bhd, private waste contractors are responsible for more than $50 \%$ of the total amount of waste collected. Community collection initiatives so called community self-help or "gotongroyong" activities also have a role in collection activities. Collections times vary from 2-3 times a week, and collection methods will also vary, common collection points e. g. containers where household are required to bring their waste in front of the house for easy collection. Door to door is another common collection method in Selangor especially for individual houses and link houses (Karen et al. 2003).

\subsection{Waste recycling in Malaysia}

In Malaysia, there are three types of recyclables such as Paper, plastics and bottles, but very little of the waste is recycled. In Kuala Lumpur for example, the current recycling rate is at 4. $5 \%$ of the waste generated. There is a plan to increase it to $16 \%$ by 2005 and $20 \%$ by 2020 (MHLG 2003), which is still valid till date.

A newspaper article published in The New Sunday Times, describes the Malaysia attitude towards recycling as a Not-In-My-Backyard (NIMBY) syndrome when it comes to issues of waste. People are also wary but still Malaysians only recycle less than $5 \%$ of all the waste (New Sunday Times 2002). This opinion is supported by other sources that claim that the waste consciousness in Malaysia is poor, and most people don't wish to take a more personal endeavour in a matter mostly associated with dirt, filth and odours. 
However true this statement may be, Malaysians have begun to recycle more as Malaysia launched first official recycling program in the peninsular Malaysia at sometimes in 1993 and was initiated by the MHLG. The stated objectives of the national recycling program was (i) to divert valuable resource in the waste stream from disposal and (ii) to help control cost of managing waste (Karen et al. 2003). The recycling program of most Local Government was envisioned as comprising of setting up of buy-back centres and the placement of drop off containers for recyclables at strategic locations such as schools, shopping malls, and so on. According to the report at the start of the national recycling program, 23 Local Government of peninsular Malaysia had volunteered to become participants of the program. But because of poor planning and lack of public participations the number of participants of the program declined to only 10 Local Government in 1998, many of the Local Government then chose not to continue with their recycling program.

The Ministry of Housing and Local Government (MHLG) re-launched the recycling programs in December 2000 to make a difference from the first failed launching of the program. In this second launching of the recycling program, participants were chosen by the MHLG, 29 Local Government of Peninsular Malaysia were chosen based on several criteria. One of these criteria was the volume of waste generated by the municipalities. MHLG provided every participant with special drop-of containers for recyclables and these containers must be placed at strategic locations of the municipalities.

To encourage public participation in this second recycling program, the MHLG engaged the services of one of the local public relation company in the city to carry out productions of pamphlets, posters and billboards, and commercial advertisement, and even recycling song to spice up the occasion. Also in addition to this, many of the major cities in Malaysia several buy-back centres established for easy deposition of recycling materials.

Another big difference in this second national program was the MHLG involved several companies that were known to be major producers of recyclable materials to participate in the recycling program. It initially involved only 23 municipalities when the program was first launched but later evolved up to 145 municipalities across the country. The main objectives are to reduce the costs of solid waste management/operation as well as to conserve resources.

Although recycling activities could be said to be on the rise, the materials recycling industry in Malaysia is demanding much larger quantities of recyclables. For example, Malaysia News Print Industries Sdn Bhd was forced to import 50\% of its materials, and Kuala Lumpur Glass Manufacturing Sdn Bhd also imported 20\% of their materials (New Sunday Times 2002). This data is still same as the material recycling rate is still 5\% till now, and raw material is not enough for these local companies.

\subsection{Waste treatment}

In Malaysia waste treatment and disposal facilities for waste in general is still lacking behind. The few incinerators that do exist do not have the capacity to deal with the exiting amount of waste and direct dumping are therefore the most applied method to dispose waste. No waste to energy facilities exists in Malaysia; although composting alternatives are being studied but no concrete activities have been undertaken (CAP 2001). Plans are underway to construct several new incineration plants in Malaysia; public opposition plays a large role in the 
approval of incineration site. One incineration is located in Southern Kuala Lumpur with a capacity of 1.500 tons/day, taking about $50 \%$ of Kuala Lumpur's daily waste generations.

In 1990 there were about 230 Landfills in Malaysia with an average of 15 hectares each. More than $80 \%$ of the landfills have an estimated remaining lifetime of two years. Almost all landfills in Malaysia are developed and operated on ad-hoc basis and the management and operation are generally poor as a result of this. About $60 \%$ are open dumps and do not have adequate facilities such as weighing bright, fence and cover materials. Furthermore, no site suitability studies have been undertaken and there is a lack of pollution control and measuring in particular for leachate and gas emissions (Karen et al. 2003).

\section{WASTE RECYCLING IN DEVELOPING COUNTRIES}

Developing countries in Asia are still backward on the issues of waste recycling as there is not much awareness of waste recycling and also ineffective policies. But in many developing countries of Asia, municipal solid wastes contain around 50\% organic matters and 30\% recyclable materials on an average, leading to a potential of recycling $80 \%$ of the total wastes (Habitat 1994a). In comparison to industrialised nations, these wastes are tense and are potentially composed of high moisture contents because of their origins in organic materials (Habitat 1994b). The per capita waste generation rate in developing countries are lower than their industrialised counterparts because of the comparative lower level of prosperity and consumption, and widespread recovery and reuse of materials before and during collection (Jindal 1998). A growth in urban population and an increase in consumption level result in increased waste generation as well, while industrialisation and modernisation result in a change in the waste compositions as materials such as plastic bags replace traditional banana leaves for packaging. Uncontrolled dumping is widespread in many Asian countries because of rapid urbanisation on one hand and shortage of landfill sites for a lack of funding and resources on the other (Jindal 1998). Separation of household wastes is unpopular in developing countries because of the people's perception of considering handling of wastes as something being 'below an accepted level of social dignity' (Habitat 1994b).

The absence of separation of solid wastes at source increase inefficiency in the recycling cycle and as a consequence the waste materials become contaminated and dispersed (Jindal 1998). In comparison to wastes picked out of mixed waste streams, recycling of wastes through separation at source provide materials that are of better quality (Furedy 1997). However, separation at source is a relatively new theme in the study on waste pickers. In order to reduce the waste disposal cost, burden on landfills and impacts on environment, the 4 Rs of waste management, namely waste reduction, reuse, recycle and recovery have been introduced and promoted.

Among many benefits, the environmental benefits of these 4Rs include a reduction of greenhouse gases, a reduction of air, water and land pollution, preservation of water, energy and other resources, and a reduction of quantity of wastes requiring disposal. Recycling industries in the major cities of Asia already possess the technological skills and equipments to process for recycling most kinds of wastes (Habitat 1994b). However, a significant quantity of solid wastes still remain for disposal in these countries, indicating that there exists a potential to recycle a larger quantity of wastes (Jindal 1994). A waste management study conducted in Jakarta, Kuala Lumpur, Bangkok, Manila and Karachi indicate that the average waste recycling rate for these cities is $7.5 \%$ against an estimated potential of 70-80\% (Habitat 1994a). 
The feasibility of full scale recycling operations there depends of local circumstances as well as organisational and economic considerations (Jindal1998). The success story of hundreds of reprocessing enterprises in the developing nations demonstrates the feasibility of recycling ventures (Ladinois and Klundert 1995). However, virtually all of the opportunities for easy and profitable recovery have already been exploited (Jindal 1998). Establishing recycling as a viable venture is a challenging task because of the collection, transportation, sorting, cleaning and processing costs required to upgrade the recycled material quality (Jindal et al. 1997).

Waste management planners who are interested to increase the possibility of waste recovery must address the challenges associated with the mixed wastes, which constitute most of the solid wastes that are disposed off without any recovery (Janeen 2004). Waste is viewed as a valuable resource when an economic incentive is associated with it. However, an economic incentive to recover materials exist when the materials are pre-separated beforehand, concentrated and comparatively uncontaminated, such as in the industrial sector where the materials contain a high inherent value and the processing cost is also relatively low (Janeen 2004). Provided that the investment requirements are reasonably low, waste materials are fairly cheap and the production process is relatively reliable and technologically not challenging, local small processing industries can make reasonable amounts of profit (Lardinouis and Van de Klundert 1995).

\subsection{Informal sectors and waste recycling}

The division of waste collectors and dealers into "formal" and "informal" sectors have been elaborated in details in various academic literatures, predominantly with reference to housing and employment. The "formal" sector refers to public or private sector corporations and registered businesses with capital investment, technological equipments and an organised labour force governed by labour laws. The "informal" sector, on the other hand, refers to unregistered and unregulated activities of waste collection and processing by individuals or small-scale family enterprises with low capital investment, local materials and labour intensive ways of work (Furedy 1989).

In most cities of the developing countries of Asia, the informal sector predominantly manages the resource recovery (Jindal 1998). These labour intensive waste recycling activities help generate employment and are cheaper to operate than their western counterparts (Janeen 2004). The informal sector is commonplace in these countries not because of ecological concerns, but as a means of alleviating poverty and improving the economic livelihood of people (Janeen 2004). Materials of value are recovered at different stages of the waste management cycle, such as storage, collection, transfer and disposal. Although it may apparently seem casual, the waste recovery activities by the informal sector can be highly organised (Jindal 1998). Estimates from Indonesian cities alone show that the waste pickers reduce refuse quantities by a third (Janeen 2004).

It is not known the number of people that participate in informal recycling and the quantity of waste they reduce in the Selangor yet, but few numbers of people are engaged in the informal sector. Malaysia could be seen collecting recyclable waste at bus stop, illegal dumping sites, etc. The reason for the few numbers are not farfetched, the high economic growth witnessed in the country over a decade and people's attitude towards waste pickers as people with no education and mental derailed and thus look down on them. Also, a high level 
of specialisation in materials selected for recovery might be found in addition to a high level of creativity involved with home based recycling activities (Furedy 1998). Roaming waste buyers travel door to door to purchase household waste items. The waste pickers recover materials of value along the streets at transfer stations and dump sites. Municipal waste collectors also salvage materials of value in some countries during the collection (Jindal 1998). These materials are first sold to the waste dealers, who in turn sell them to various wholesalers and manufacturers (Janeen 2004).

Waste pickers in many developing countries of Asia do not use any safety equipment, such as facemasks, earplugs, gloves and proper footwear, which means they should be provided with health and safety related education (Furedy 1998). The lack of necessary precautionary measures, unsafe practices, noise, high temperature, polluted atmosphere such as dust and hazardous chemicals -, contaminated wastes and long working hours pose health hazards to the waste pickers (Lardinois and Klunder 1995). Professional standards and health and labour regulations are in need of further improvements, but even when regulations exist, some of the informal recycling activities do not comply with them (Lardinois and Klunder 1995). In general, lack of proper enforcement of legislations is a common problem in most of the developing countries of Asia. There is need to educate them on the implications of sorting waste without precautionary measures (Jindal 1998).

\subsection{Economy of waste recycling}

The economic importance of waste recycling cannot be over emphasized, but it can play a crucial role in a community where it is understood and also well implemented. Recycling of wastes can reduce the waste disposal cost for local authorities by extending the lifecycle of landfills, reducing the need to invest in vehicles and transportation equipments, reducing vehicle operations and maintenance cost, and reducing fuel consumption for transportation of wastes (Habitat 1994a). Businesses are provided with low-cost raw materials. In several countries businesses, particularly steel, paper and glass industries depend on recyclable materials (Jindal et al. 1997). The reliance on recycled materials cuts the need of importing raw materials.

The local circumstances affect the attractiveness of recycling for neighbouring entrepreneurs. The costs for using recycled raw materials can be higher than virgin materials if the later are available in a concentrated area and consist of a more homogenous composition (Janeen 2004). It is easy to fins markets for readily accessible and high quality waste materials. Mixed contaminated and low-value waste materials offer less potentials for recovery and reprocessing, a recycling rate of 7.5 per cent contributes to annual cost reduction of more than US\$ 1 million in each city; therefore, the potential saving of cost from recycling has improved the recycling rate even greater (Habitat 1994a).

An average of US\$ 1 million is spent annually in Bangkok, Jakarta, Kuala Lumpur, Karachi and Manila for collection and disposal of wastes in each of these cities (Habitat 1994). The stages of collection and transportation are usually the most expensive components of the overall system (Janeen 2004). Although the municipal authorities spend 30 to 50 per cent of their total operating budget on solid waste management, they are usually able to collect only 60 to 70 per cent of the solid wastes in their respective cities (Habitat 1994a). It has been estimated that approximately 1 per cent of the urban population are involved in the waste recycling sector, but if it reaches its full potentials it is believed that this sector can employ up to 2 to 3 per cent of the urban population (Habitat 1994b). 
Recycling is a labour intensive industry with a relatively low start-up cost that provides employment opportunities and income generation opportunities for a significant number of people as waste pickers, itinerant waste purchasers, waste dealers, and workers employed at recycling enterprises, their managers and entrepreneurs (Lardinois and Van de Klundert 1995). The waste recycling sector often serves as an entry point into the urban economy that provides participants with economic benefits, on-the-job training, business opportunities and a higher social status (Janeen 2004).

\section{WASTE RECYCLING IN DEVELOPED COUNTRIES}

Developed countries have achieved a high rate of above $50 \%$ of waste recycling in their areas (Child 2004). Many studies have been conducted on recycling and waste diversion over the past decades in developed countries. However, recycling program and approaches to waste diversion differs in these countries based on several issues.

\subsection{Economics of Recycling}

Many municipalities and cities continue to tax for solid waste services, creating an invisible cost to consumers. Unit pricing has been utilized as a method for decreasing and increasing recycling rates in developed countries. This strategy increases the cost to households is based upon the reality of resource costs and environmental impacts. As 'pay-as-you-throw-away' become a commonality program in the 1990s. Athens in Ohio State, US implemented this method in 1990 (Reschovsky and Stone 1994). It appears from the literature to be most effective when accompanied by a recycling program that is understood by the citizenry especially curbside pickup.

Quantity-based pricing of waste disposal was found to impact recycling behaviour, with greatest increases when curbside recycling was implemented. Hong and Adams (1993) examined price incentives and their impact on recycling in Portland, Oregon. They found that increases in the charges according to waste generated by communities and disposed were positively related to recycling increases. It's understood that people chose to divert their waste into recycling. The authors concluded that solid waste costs were so small to overall household budgets that recycling was an important component of cost reductions rather than the result of a conscious effort to decrease consumption.

A follow-up study by Hong and Adams (1999) examined container size pricing schemes and their impacts on recycling. With solid waste pricing in Portland, Oregon significantly higher than the current charge in Athens, $\$ 35.90$ for two 32-gallon cans as compared to $\$ 9.50$. The authors suggest that unit pricing itself is not effective in diverting waste. However, when accompanied by 'aggressive recycling programs' recycling may increase while solid waste collection sources decrease. They found that when households contract for a given volume of solid waste disposal container size, recycling rates are positively impacted. With a wide variety of choices and very large container sizes and costs, it would see enlightenment is a key component when providing solid waste services within a community.

Jenkins et al. (2003) researched curbside and drop-off recycling effectiveness among middle and upper income households in 20 metropolitan statically areas. Curbside recycling was found to be the most effective as compared to transporting specific recycling materials to 
drop off recycling services. Drop-off recycling services maintained an important role in recycling for a community with constrains that would not allow curbside recycling. The impact of price unit pricing was found to increase recycling and consumption choices towards recyclable materials but may be different to detect by examination the $\%$ of a material a household recycles. The findings were supported by a unit pricing project in Marietta (1993-1994) and studies by the environmental Protection Agency as well as Van Houtven and Morris (1999) receptacle and bag programs were implemented and compared through weighting.

A cost efficiency analysis of diverting waste through "throw away" and increased recycling programs cost, supported unit pricing with $36 \%$ reductions bags and $14 \%$ by receptacles. The cost of recycling as compared to cost of solid waste collection and disposal was examined by Folz (1999). Viewing recycling as the environmental success story of the 1990s decade, the author advises that showing cost effectiveness is a key motivator at both the individual and municipal level of solid waste management. A study of recycling coordinators indicated that budget discussions were often directed by the belief that recycling was not cost-effective and thereby acted to validate ending recycling programs. Comparing costs of recycling to solid waste disposal unit costs indicated that recycling was very competitive, if not lower, in comparison to waste disposal and therefore should be considered economic incentive.

As recycling is the primary means of diverting solid waste, the literature suggests that city and state government should simultaneously allocate funding to maximize recycling and actively promote decreasing barriers. Macdonald and Vopni (1994) suggest that the centralized separation of recycled materials is less expensive for a municipality than a source separation and can potentially increase recycling rates. Kinnaman and Fullerton (2000) studied 114 communities with a user fee for a solid waste disposal. These were viewed as having benefited effects reducing solid waste into landfill, raising revenue and providing incentives for recycling, composting and source reduction.

The authors also estimate that demand for garbage collection and recycling collection as a comparable function of the price of garbage. The user fee decreases the weight of solid waste more than it increased the weight of recycling. Local policy choices found that raising solid waste rates from 0 to $\$ 1$ per bag results in a 412 pound decrease per capita while recycling increased by 30 pounds per capital. Regarding missing solid waste, the authors concluded that source reduction, composting and illegal dumping are all potential consequences of user fees, that reduces per capital solid waste disposal. The authors also assert that the creation of local policy has a greater impact on solid waste decision rather than policy made at the state or national government level.

Similarly, Callan and Thomas (1997) believe that Local Government solid waste policies are an appropriate method to utilize when implementing programs as compared to larger State mandated policies. Each community, its population and region specific influences are viewed as effecting local responses and outcomes. Recycling and unit pricing research in Massachusetts found that a community implementing unit pricing can expect an annual recycling rate increase of 6.6 points. An additional increase of 5.5 points are predicted if the pricing plan is accompanied by the provision of curbside recycling services. The authors also propose that economic and demography can influence the success of a recycling, thus officials should make informal local policy decisions utilizing this information and design initiatives to accommodate the population of their city or municipality. Interesting and 
importantly, the state of Massachusetts has a material recycling facility that provides free recycling and marketing facilities to 97 communities in western Massachusetts, recycling approximately 200tons of materials per day! This is a privately run, state owned facility. The accompaniment of this to the State Solid Waste Master Plan increased recycling programs within various municipalities from 190 to 341 in 1992. This is a substantial and productive approach to increase recycling in the state. There is need for feedback for effective recycling in a community for effective recycling programs to be achieved (Loraine 2006).

In a study households in a community group signed a letter making public commitments to recycle and giving permission to publish their names in a local Paper while feedbacks on pounds of recyclable papers generated. A combined intervention and no intervention group were observed. Combined intervention and feedback group intervention were found to increase recycling while the other groups did not (Deleon and Fuqual 1995). Oskamp et al. (1991) found that home owners and separate-house dwellers were more likely to recycle than residents of apartments if the community is enlightened and educated. This is applicable to individuals as they typically rent apartment or live collaboratively in houses.

\subsection{Policy effects on recycling}

Policy implementation with regard to solid waste recycling appears to be strongly correlated with the community where the problem is development. Various methodologies have been leading to the conclusion that it is important to have citizen impute in policy formation, development of diversionary goals, education, and outreach campaigns. Folz et al. (1991) studied on New Jersey and found that policy and community involvements were very important, with citizens likely to participate in collective efforts when they are involved in policy initiation and program design. The state implemented a mandatory recycling program in 1987 requiring each municipality to establish rules and regulations for the separation and collection of designated waste.

The study suggested that recycling convenience was a key inducement. Recycling containers should be placed in accessible locations each such as shopping malls, shopping centres, grocery stores and schools. In addition, participants emphasized education program to inform the public about the advantages of recycling as well as the publicity campaign for recycling information. Fines were seen as an effective extrinsic motivator (Nyamwange 1996). Recycling was suggested to be a multifunctional activity and thus education and campaigns should include a persuasive approach that involves multiple dimensions. Individuals with environmental motivations were found to maintain the responsibility of recycling (Loraine 2006).

Scott (1999) worked on four communities in the Toronto area exploring demographics, motivation, knowledge and environmental attitudes. He suggested that marketing strategies as a result of this work should include providing up-to-date program information, materials and sorting techniques.

Empirical studies reviewed by Schultz et al. (1995) identified four areas of recycling predictors - environmental attitudes, knowledge, demographic, and personality variables. The authors suggested that recycling should be treated as a multifaceted pattern of behaviour and community leaders should be involved in shaping public policy. 
Oskamp et al. (1998) mentioned that educational efforts should focus on the benefits of recycling, relating it to environmental concerns within the community and country, emphasize its importance with regard to energy needs, landfill and natural resources impacts. Utilizing European data by Yi et al. (1999) found that waste behaviour was very specific to the culture and variations found within households. This is critical to understanding the complexities of implementing recycling programs. Replication in various settings was viewed as difficult with the suggestion that programs must be developed for specifics of the community.

A national mailings of respondents on the measurement of ecological conscious consumer behaviour found that education regarding environmental issues will encourage behaviours such as recycling and environmentally appropriate consumer choices (Roberts and Bacon 1997). Extrinsic motivation through verbal commitments was utilized as an approach to increase curbside recycling among community members (Loraine 2006). A study by the International Council for Local Initiatives Council, that provides liaison services in environmental management to Local Governments, revealed that Governments need to clarify their role in solid waste management and direct policy input was needed by waste disposers and private sector product manufactures, encouraging incentives for source separation, markets for recyclables and allocating the increased cost of waste management (Macdonald and Vopni 1994).

Oskamp et al. (1996) concluded that residents will participate in recycling if the system is convenient, as well as when large variety of items is collected. Menses and Palacio (2003-2004) explored encouraging and strengthening recycling behavioural changes. Reward techniques verses block leader techniques that included a written agreement encouraged the participant to fulfil the act of recycling. Rewards were seen as minimizing environmental impacts while block leaders acted as a constant environmental educational source.

Noehammer and Byer (1997) analysed the effectiveness of municipal recycling programs was when researching of mandatory versus voluntary program materials collected and number of segregations, collection containers provided, collection frequency, collection coordination with solid waste retrieval, collection vehicle type, presence of education program, economic incentives. The study suggests that designing programs must first address the needs and goals of the community and consider the effectiveness of design variables.

Loraine (2006) studied residential curbside recycling programs throughout Toronto, evaluated the materials recovery rate utilizing two factors as mandatory verse voluntary recycling and convenience as measured by container provision, collection frequency and collection day relative to municipal solid waste collection. The study found that collection rates increased when mandatory programs were implemented. This may or not be a result of the implementation of the law or may be related to the increased publicity around the mandatory ordinance. Provision of containers did create a statistically different outcome, while interestingly, recycling collection on the same day as the solid waste collection appeared to have a negative effect on recycling rates.

When evaluating behaviour in suburban and urban communities, Lansana (1993) concluded that recycling programs must be tailored to fit the diversity in needs and preferences of specific communities while a careful planning and implementation of solid waste management and program. The more information and awareness of the recycling and solid waste program within the community, the less likely that residents will complain about 
the time and inconveniences associated with the recycling activity, which increase the tendency of participation by the community.

Lober's studies on source reduction included bringing bags to the grocery rather than utilizing a store offered bag, refusing grocery when not needed, and preference of cloth diapers over disposable diapers, refilling laundry products rather than buying new containers each time. The result indicates participants preferred recycling to source reduction while the very term generated confusion and a lack of agreement.

Recycling is still an important component of waste reduction and diversion, as well as an entryway for participants in environmental awareness. Recycling has the potentials to be a daily activity, taught within the elementary classroom and home environment. Individuals recycle for different reasons, but the basic purpose is that of environmental concerns and economy. It can be used as an entrée to other environmental issues as reduced consumption, energy issues, water and air pollution, land use and global warning. Recycling is a better way of disposing waste generated at the individual level than simply throwing it to perpetual landfills which is not sustainable. It involves a complex claim of behaviours that involves state legislation and funding and Local Government support through policy decisions, education and distribution of information and services that encourage recycling by citizens and community members. Finally it does not make sense to throw away waste when it can be recycled.

\section{MALAYSIA IN THE TRANSITION OF WASTE RECYCLING}

Malaysia like every other developing country is facing problem of waste management. Waste management and recycling is largely influenced by the lack of planning and implementation in accord with the waste management hierarchy of reduce, reuse and recycling (3R) (Agamuthu et al. 2009). This has resulted in a waste management system based almost on waste disposal on landfills. Solid waste disposal is therefore one of the major issues in Malaysia waste management practices today.

Many landfills are not properly managed and maintained, and few or none of the landfills have EIA or other site suitability evaluations performed. Due to this, landfills are often located too close to residential areas or other public areas. Many landfills are also located near streams and rivers, which not only cause river pollutions, but also ground water is at risk of contaminations. Uncontrolled emissions of greenhouse gasses are also problematic-especially methane. Waste are dumped in rivers, drains and streams that often not collected, and little or nothing or no waste is composting take place which means that the waste takes up spaces, and landfill life time are often much shorter than their expected time of existence. The issue of illegal dumping is also relevant in this regard (Wai 2007).

A significant challenge facing developing countries is the search for appropriate solution for collecting, treating and disposal of waste or reuse of waste materials generated in municipal and community areas. Recycling of waste is a challenge confronting many developing countries as urban cities are in the increase of population and so is the waste generated. There is low level of recycling in many developing countries; either because of ignorance or apathy towards recycling (Wai 2007).

Recently the Selangor state government is considering a proposal to recycle and turn it into an income generating venture as most local council spend up to $30 \%$ of their local 
budget on rubbish collection and some up to 60\% (Daily Metro 2008). The recent creation of a National Solid Waste Department is stepping in the right direction as this will relieve the Local of the financial burden of managing waste (Yahaya 2007a).

The traditional method that the country has been using is to use the landfills for waste disposal of waste, and overtime buries them with soil. But Landfills require huge plots of land and usually fill up very quickly. Some big landfills have been closed down due to reaching their capacity, as well as the suitability of the locations which use to be far away from residential areas, but are no more due to population and township growth. Some examples are the Kelana Jaya dumpsite (now filled with condos, a stadium and commercial development). Subang Airport road used to stink badly whenever you use the road to airport, but is now a residential area with condos and houses. Sri Kembangaan/ Air Hitan were also closed down and also Selaying Landfills (Wai 2007).

The alternatives of landfills like incinerators, particularly of gigantic types but still unknown status Broga incinerator in Semenyih which courted controversy due to questions about its location in a catchment area as well as the Japanese contractor which has a questionable project back in his home country. Nobody likes to have a waste processing plant behind his or her backyard. The incinerator was first proposed to be in Puchong but was relocated due to residence and political pressures. Something has to be done to cope with its ultimate disposal. The government is to tackle the problem even though the idea of smaller, more efficient and manageable incinerator would be idea than the biggest incinerator.

People living in the peninsula especially Selangor should be encouraged to cultivate the habit of reducing waste by recycling as in developed countries where it has become of thing habitually even from younger age (Wai 2007). The high economic growth in recent years in Selangor requires a sustainable means of managing waste. The recently created National Waste Department has been a way forward to that effect.

Selangor government could borrow a leaf from Europe where recycling has become a habit of life as in the case of the Cliff Borough Council in East London. The Cliff Borough Council in East London, in 2001-2002, recycling rate was just $9.7 \%$ but it jumped to $48 \%$ in 2003-2004, and reached to 50\% by December 2004, suggesting that CBC may become UK's biggest performing local authority. The study of RCR suggested that a well-designed communication campaign and an effective marketing strategy is the key to achieving success in recycling programs.

There is a proposal by the government for some years to enforce compulsory garbage separation in Selangor. It is not an easy thing to do even though it could have succeeded in some countries like Taiwan, as their culture values and geographical location differs from that of Malaysia. The fact that policy worked in Taiwan does not mean it workshere; therefore Malaysia should find policy that should be wholly accepted by her citizenry (Wai 2007).

The state has now intensified its effort through integrated waste management system of reducing waste through sustainable waste management of $3 \mathrm{R}$ and final disposal. Awareness of this program is being carried out through campaigns, mass media and lectures. At the same time the State Government is facilitating through the Ministry of Housing and Local Government to provide facilities such as waste bins and collection centres households (MHLG 2006). 
Recently residents in Selangor are required to separate their waste into organic and inorganic waste for easy collections and recycling by Alam Flora Sdn Bhd. Although the new rule attracts no penalty for failing to do so, household waste could be refused to be collected by Alam Flora for failing to separate their waste accordingly (Bavani 2009). On the other hand Shopping Malls in the state are now required not to give plastic bags on every last Saturday of the month to shoppers. Shoppers who insist on collecting bags are required to pay 20 cents for each plastic bag collected and the money will be channelled to the charity homes in Selangor chosen by the state. Below are Figures 2 and 3 showing the current recycling rate and recycling target for Selangor in the year 2020.

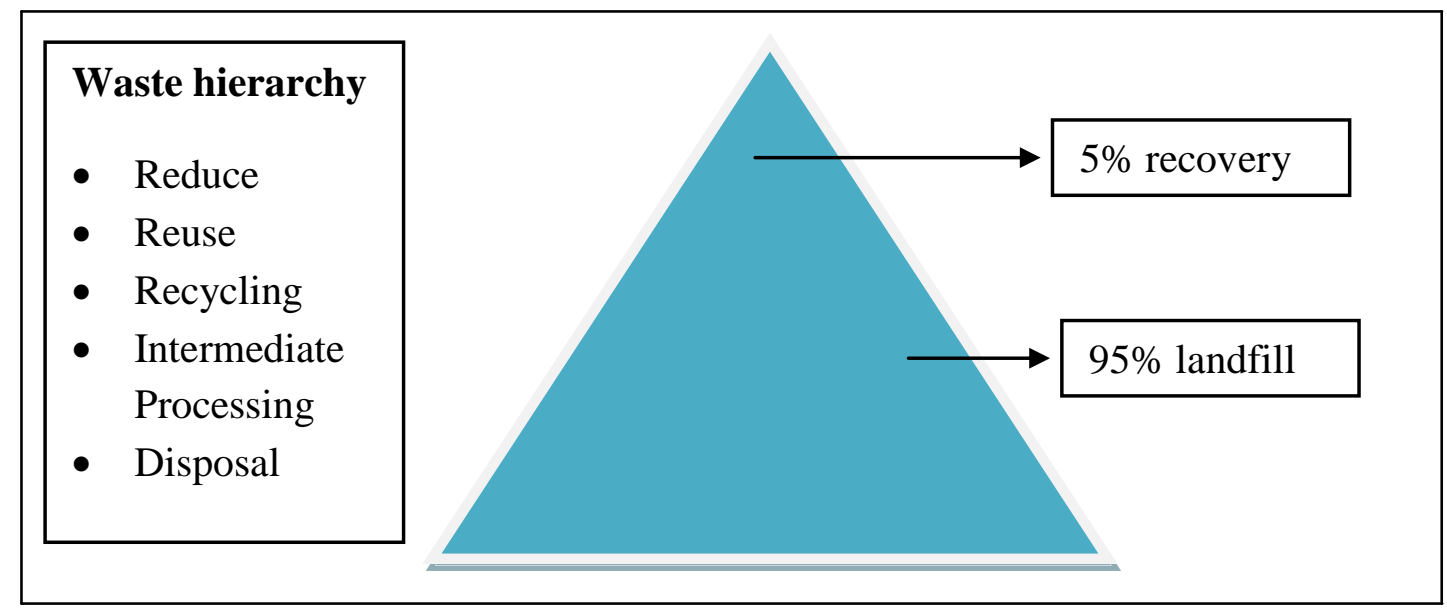

Figure 2: The current waste management system in Selangor

Source: Ministry of Housing and Local Government (2003)

From the figure 2, it shows that the current waste recycling and recovery is only 5\% of the total waste generated in the state while the rest $95 \%$ is sent to landfill. Land has been the traditional method system of waste disposal in Selangor.

This trend has been going on for ages in Malaysia, as there are abundant lands to deposit waste. But with the increase in population and high growth of economy in Malaysia in the last decade, there are calls for a more sustainable system to dispose waste without much environmental effect as land is running out and becoming expensive to build landfills.

The use of "sustainable landfills" by some authorities could have been the reason behind the recent construction of the biggest landfill in Malaysia, the Bukit Tagar sanitary landfill in Ulu Selangor $50 \mathrm{~km}$ north from Kuala Lumpur in Selangor which started operation in 2005 occupying a capacity of 1,700 acres of land with 120 metric tons of air space.

But the use of such term by some authorities suggests that the concept of sustainability is not well understood correctly. How could landfills which take objects, many manufactured from finite resource and bury them in the ground under conditions which generate gases and liquids for periods which are in excess of the present generation be considered sustainable? (Waite 1995)

Malaysia has to develop sustainable methods of waste management, but at the same time accept that achieving this goal is long way off. But for the moment recycling is the only sustainable method to reduce waste. 
Figure 3 shows the strategic recycling target of Selangor Government with integrated waste management of reduce, reuse, recycling, intermediate processing and final disposal to increase waste recycling rate and recovery in the 8MP till 2020. This target is feasible if appropriate policies and technology are in place.

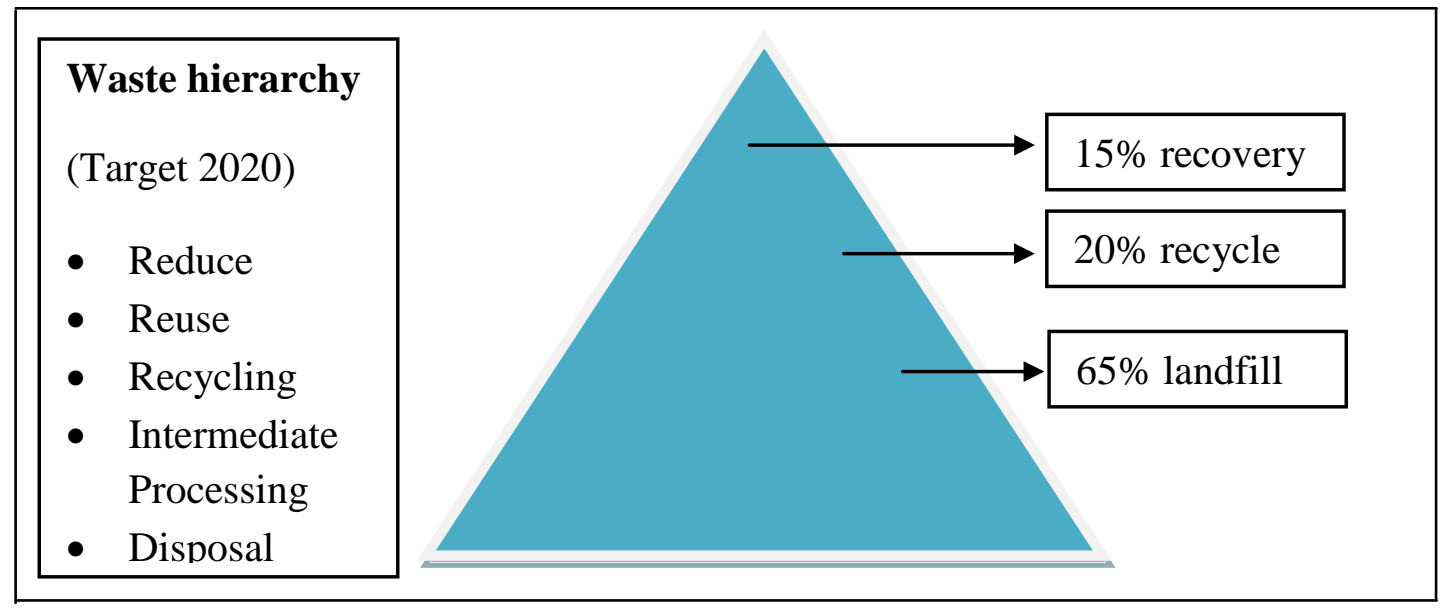

Figure 3 Waste recycling targets for Selangor in the 8MP for 2020

Source: Ministry of Housing and Local Government (2003)

There is still insufficient emphasis being played by local authorities and others on the whole of question of re-use. We are all familiar with these sticky labels that enable us to reuse old envelopes, but have many of operators of business or local authorities that can reuse our items. That notwithstanding, the Selangor Government is encouraging, households; offices to either give out their old materials to those in need when refurnishing their offices or homes than throwing it into the waste stream. Reusable bags are sold at some shopping malls that are also biodegradable. People are encouraged to buy household items that are refillable, like hair cream, beverages and some soft drinks with plastic bottles etc. so as to reduce waste at households' level.

Recycling has become a known issue since the launching of the first national recycling program in 1993 and the launched of it in December 2000 in Malaysia. The Selangor Government has in many ways disseminating this massage to her citizens, that recycling is a sustainable means of managing waste so as to attain the state target of $20 \%$ diversion of waste sent to landfills in 2020.

This is being made possible by provisions of waste bins at strategic places in the state and privatizing waste management. Households are encouraged to separate their waste into wet and dry waste for easy collections and recycling, though not compulsory. But for Malaysia to achieve her target of $20 \%$ recycling rate in 2020 more proactive measures has to be taken by making waste separation compulsory at household levels and with the imposition of fines for failing to separate their waste.

Other waste hierarchy plans of Selangor to be achieved in 2020 is the establishing of an intermediate processing facility in state where recyclable materials will be sorted by types, compacted, baled and sold to many manufacturing companies in the countries that use 
secondary raw materials for productions and also for export. Intermediate processing facilities will process and market newspapers, mixed paper, cardboard, plastic, tin can, glass and aluminium received from various parts of the state of the country and for export as well.

\subsection{Post waste material management and disposal}

Transportation and collections of waste are another concern in Malaysian waste management practices, especially in urban areas, e. g Kuala Lumpur, where some streets are narrow and compactor trucks are unable to pass (Mokhtar et al. 2002). The most visible part of solidwaste management is collection and transportation. After the collection of waste from their homes, offices, or industries people have no interest in where it is taken or what is done to it. Very few residents have seen disposal sites such as incinerators or landfills. Door-to-door collection is provided to all landed properties. Those living in apartments and illegal settlements have to bring their waste to the community bins. Generally the collection of waste is done three times a week on alternate days except on Sunday. In some apartments, shops, and business offices the collection of waste is done daily, except Sundays. In vegetable markets the collection is done daily including Sunday. In areas of unplanned or illegal settlements, collection is done once or twice a week.

But on festive occasions such as Chinese New Year or the end of Ramadan (fasting) month, frequent collection service is provided. The collection and transportation system in Malaysia is fairly common. From the 1980s this activity has been privatized (Lee 2007). Since major settlements are under local authorities, collection and transportation is available to all residents except those living in isolated areas such as the hilly region. On Penang Island, the infrastructure is relatively better, and almost $95 \%$ of the residents are provided with a solid-waste collection service. There is no special service provided to collect garden waste as it is included in household waste. Sometimes it is left along the roadside or burned. Some bigger municipal authorities provide a special service once a week to collect garden waste.

For this service, the owners need to cut the waste into manageable pieces or bag the leaves to facilitate collection. On-call, chargeable service is also available in some local authorities. The local authorities are required to submit reports on the status of recycling in their areas. Unfortunately, according to the ministry, the response has been poor, and with unreliable data (New Strait Times 2001).

\subsection{Future plan for sustainable waste management practices in Malaysia}

The SWM Act 2007 introduced by the Government which has now become legal emphasis compulsory system of waste hierarchic of the 3Rs: reduce, reuse, and recycle. This is an important campaign included in the Act. The implementation and enforcement of the 3Rs are also listed in the Act under. Solid waste generators are required to reduce the generation of solid waste; to use environmentally friendly materials; to limit the generation, import, use, discharge, and disposal of specified products; to implement coding and labelling on products to promote recycling; and to utilize any method to reduce the adverse impacts of municipal solid waste on the environment, i. e. to reduce, reuse, and recycle of MSW (Lee 2007). Therefore adoption of the SWM Act encompassing solutions for all the identified gaps and implementation of the specific waste component management options is expected to significantly narrow the gaps and enhance the MSW management situation in Malaysia to be on par with other developed world. 
Although waste minimization is emphasized in the Act, the techniques to reduce waste generation are not specified and the options are too generalized (Agamuthu et al. 2009). Failure to comply with the law will make the offender liable to a fine of up to RM10,000 (US\$2632) or up to 6 months imprisonment, or both. The government of Malaysia has plans to manage household waste efficiently to ensure a clean, fresh, and sustainable environment. For all these initiatives yield the desirable results, it should be followed by monitoring to insure if the goals set up are being achieved.

These operators will be subjected to a stringent performance management regime linked to KPIs such as the coverage of service, compliance to schedule and frequency of collection, number of complaints and soiling of roads from leachate. Payments to concessionaires will be linked to the achievement of these KPIs. Contract negotiations with the concessionaires are expected to be completed by end 2010. Measures to drive efficiencies in operations will include optimizing transportation costs by utilising the best available route to the disposal sites, the most suitable system of vehicle and the optimum number of crew. And standard 120-litre bins for every household will also reduce the problem of leachates and improve overall hygiene conditions. Under this effort over 5,600 shared premises including wet markets, parks, food courts and other such facilities will be provided frequent and reliable cleaning services. This is expected to provide a conducive and attractive environment for people to congregate as they carry out their daily activities.

Again the new solid waste acts, incentives such as a deposit refund scheme and take back will be implemented. This system allows consumers to receive refunds upon return of used recyclable products and requires manufacturers and supplier to take back specified products after (10th MP,2010).

\section{CONCLUSIONS AND RECOMMENDATIONS}

Developing countries are still far behind when compared with developed countries as the informal sector still plays a significant role in waste recycling but in developed countries the situation is different (Habitat 1994a). This is because of the health implication associated with informal waste disposal and also the economic advancement of the developed countries does not encourage informal waste recycling methods. The developing countries lack effective recycling policies as leaders of communities are not involved in policy formation that affects them (Folz and Hazlett 1991). Without following the western model blindly, the developing countries should follow certain policies based on community values, and appropriate local technology (Polprasert 1998).

Educated community tends to understand their roles towards environmental issues unlike communities that are not educated. Recycling convenience is still lacking as some communities are without wheel bins at the shopping mall, wet market area, schools unlike developed countries where bins are placed in convenient places for easy collection (Nyamwange 1996). There is no enlightenment program to create awareness of the benefits of recycling as this contributes apathy towards recycling, whereas in developed countries it has become a thing of habit to recycle because of their environmental concern (Menses and Palacio 2005).

Developing countries tend to recycle not for the act of altruism but for economic reasons only while the developed countries recycle for their environmental consciousness and 
intrinsic believe that a clean environment is worthy activities. Volunteerism in the issue of environment is practiced among few middle class and high class members of the society (Hopper and Neilsen 1991) while this habit is inculcated among teenagers in their formatives years in school in developed countries (Ka-chi Wai 2007).

Recycling has become a way of life in developed countries resulted in high recycling rate due to policies and logistics that are user friendly. Although the economic benefits are the same, this has not been fully utilized by developing countries (Habitat 1994a).

Informal sectors still plays a major role in waste recycling in Asian developing countries because of high level of poverty. This should be reorganized and integrated into system hence due to economic reasons they will still play vital role in waste management. Recycling activities is gradually being embraced by Asian developing countries as it can help reduce disposal cost for local authorities, reducing vehicle maintenance and its economic benefits (Habitat 1994b).

Many developed countries have greatly accepted the policy of "pay-for what -you throw-away "program. Unit pricing has been an effective means to reduce waste through increasing cost for households. It is generally believed by the developed world that when you know that if you generate much waste you will pay for it. That intrinsic believe of high cost of waste disposal by households will surely compel them to be careful how to generate waste in their households and to recycle more of their waste. This policy has highly motivated households to cultivate the recycling habit more than developing countries who still look to the government to dispose waste for them as paying for the waste generated at home could have a political undertone for opposition parties.

Policy implementation whereby communities are involved in policy formation is very important for effective recycling program as it helps create sense of belonging and ensure the policies effectiveness in their locality. In addition recycling should be made mandatory rather optional and as well as source separation of waste at households. There is need for recycling convenience as it suits the community. Recycling has the potentials as seen in the review to reduce waste generation and at the same time an entrée point for participation in environmental awareness.

Malaysia can learn a lot from developed countries how their recycling rate has increased. Generally, many of the Malaysian SWM policies especially those related to waste management recycling activities have been implemented in an informal basis due to a lack of legislative empowerment. However, even though the enactment of the SWM Act in 2007 has provided the legislative framework for SWM, it is yet to be seen how effective it will be as implementation of policies has always been the bane of developing countries. Furthermore, the initial enforcement of the SWM Act is only expected to be in areas related to SWM facilities and services as opposed to SWM activities since the SWM Corporations are expected to adopt a non-regulatory approach in addressing $3 \mathrm{R}$ activities in the initial stages. There is no political will on the part of the government to introduce pay-as-you-through-away system which has been effective in many developed countries in reducing waste drastically and lack of availability of fund for policy initiatives, manpower and appropriate technology.

Consequently one of the potential key policy gaps observed in waste management policies is the delay in the formal adoption and compulsory implementation of $3 \mathrm{R}$ policies for all households in Malaysia. Source separation is not fully implemented. There is a significant 
policy gap between theory and practice since without the formal adoption or enforcement of the policies; policy implementation can only be done informally and in an ad-hoc manner by SWM stakeholders. Thus, the key challenge in the Malaysian 3R practices is gap reduction between SWM policy and its implementation either due to stakeholder acceptability of 3R policies or policy implementation obstacles from political interference or policy impracticality due to direct adoption of SWM policy practices from other countries. Why allow people to pay 20cent for plastic bag on Saturdays while there is campaign to discourage the use of plastics for shopping because of its environmental effects. This is contradictions from policy makers on the whole aim of reducing plastic use. There should be strong political will to implement policies though not convenient at the beginning but have over all benefit to the society in future. Therefore adoption of the SWM Act encompassing solutions for all the identified gaps and implementation of the specific waste component management options is expected to significantly narrow the gaps and enhance the MSW management situation in Malaysia to be on par with other developed world.

\section{REFERENCES}

Agamuthu, P. , Hamid, F. S. and Khidzir, K. 2009. "Evolution of solid waste management in Malaysia: impacts and implications of the solid waste Bill 2007," Journal of Mater Cycles Waste Management, 11: 96-103

Bavani, M. 2009. Metro, Separate your waste from June 1. April 29, 2009.

Budzik, M. Jonathan, M. Luciano, A. \& Juliana, P. 2002. Waste Management Overseas. The Malaysian experience. Dec. 2002

Callan,S. J. \& Thomas, J. M. 1997. The impact of state and local policies on the recycling effort. Eastern Economic Journal. 23 (4), 411-423.

Child, R 2004.Resource Conservation and Recycling Cliff. Borough Council Recycling Progres Report in Eastern London. P. 1-25

Connett, P. 1994. Incineration; A poor solution for the $21^{\text {st }}$ century; Slideshare publication 2010.

Consumers Association of Penang (CAP). 2001. The proposed thermal waste treatment Plant for waste management in Kg Bohol, Mukin Sungai Besi, Kuala Lumpur, http;//www. surfforever.com/sam/pressurelease/kgbohol.

Deleon, I. G. \&Faqual, R. W. 1995. The effects of public commitment and group feedback on curbside recycling. Environment and Behaviour. 27 (2), 233-250.

Folz, D. H. \&Hazlett, J. M. 1991. Public participation and recycling performance; Explaining program success. Public Administration Review 59 (4), 336-345.

Folz, D. H. 1999. Municipal recycling performance: A public sector environmental success story. Public Administration Review. 59 (4) 336-345.

Furedy, C. 1989. Urban Waste Picking in Low-Income Countries, Knowledge and Action Furedy Research and Adverting Inc. Canada.

Furedy, C. 1997. Reflections on some dilemmas concerning waste pickers and waste recoveryP ,1-7 Furedy Research and Advertising Inc. Canada.

Goldenhar, L. M. \& Connel. C. M. 1991-1992. Efforts of educational and feedback interventions on recycling knowledge, attitudes, beliefs and behavours. Journal of Environment of Environment System 20(4),321-333.

Habitat International, 1994a.Appraisal of solid waste collection and private sector involvement in Dar re Salaam City, Tanzania. Habitat International. 29 (2) 353 -366

Habitat International, 1994b.International co-operation for habitat and urban development.

Hassan, M. 2002. Environmental Management in Malaysia: E. I. A process in Malaysia. Ministry of Resources and Environment. 
Hong, S. \& Adams, R. M. 1999.Household response to price incentives for recycling some further evidence. Land Economics. 75 (4), 505-514.

Hong, S. , Adams, R. M. \& Love, H. 1993. An economic analysis of household recycling of solid waste: The case of Portland Oregon. Journal of Environmental Economics and Management. 25. 136-146.

Hopper, J. R. \& Nielsen R. M. 1991.Recycling as altruistic behavour; Normative and behaviour strategies to expand participation in a community recycling program. Environment and Behavour. 23 (2), 195-220.

Janeen, T. 2004. A case study of a hotel solid waste management in Bali, Indonesia's thesis, University of Waterloo, Ontario Canada.

Jenkins, R. R. ,Martinez. S. A. ,Palmer, K. \& Podolsky. 2003. The determinant of household recycling; A material-specific analysis of recycling program features and unit recycling. Journal of Environmental Economics and Management.25,294-318.

Jindal, B, Harada, H. \& Shikura, S. 1997. Municipal Solid waste management in Nepal: practices and challenges. Waste Management. 25 (5), 555-562.

Jindal, B. 1994.Environmental pollution control \& energy conservation. Steel Authority of India.

Jindal, B. 1998. Waste recycling policies in Hong Kong. International Journal of Material Recycling 10 (3), 205-230.

Karen, A. K. , Nash, A. May, L. C. \& Knudsen, 2003. Household Hazardous Waste Management and Stakeholder's involvement in Kuala Lumpur.

Kinnaman, T. \& Fullerton, D. 2000.Garbage and recycling with indigenous local policy. Journalof Urban Economics 48,419 - 449.

Ko-chi Wai. 2007. Being Unreasonable; Reduce, Reuse and Recycle. www_lancashire_gov_uk-environment-waste-reduction. P 1-9 (26 June 2007).

Lansana, M. 1993. A comparative analysis of curbside recycling behavour in suburban Communities. Professional Geography, 45 (2), 169-179.

Lardinois, I, \& Van de Klunder, A. 1995.Plastic Waste. Netherlands. Tools Publications and waste consultants.

Lee, G. B. 2007. Solid Waste Management: Issues and Challenges in Asia ;Published by the Asian Productivity Organization Tokyo. Japan

Lewis, E. \& Healv.Jr. H, L. 1990.Packaging and Solid Waste Management Strategies. New York American Management Association.

Lober,D. I. 1996. Municipal solid waste policy and participation in household source reduction. Waste Management and Research, 14, 125 - 145.

Loraine, A. McCosker, 2006. Barriers to recycling in Athens, Ohio. Msc thesis. College of Arts and Science of Ohio University

Macdonald, D. \& Vopni, P. 1994. Policy barriers to 50\% diversions of municipal solid waste. Waste Management and Research 12 (3), 257 - 270.

Meneses, G. \& Beerli Palacio, A. 2003-2004. Comparison of two techniques to promote recycling: Block leader verses reward .Journal of Environmental Systems. 30 (2), 105-134.

Ministry of Housing and Local Government (MHLG) 2003.Overview of solid waste management in Malaysia, Kuala Lumpur. Local Government Department.

Ministry of Housing and Local Government (MHLG) 2006.Waste management and the Challenges.Money in recycling. 2008. Daily Metro, 7 May.

Mokhtar, M. B. Peterson, P. J. \& Fariz, A. 2002.Approaches towards sustainable environmental and national resources management for ASEAN regions. Lestari, UKM Bangi, Selangor

New Strait Times, 16 April 2001. Waste management's and recycling problems; data issues 
New Sunday Times. October 2002. Not-In-My-Back-Yard Syndrome (NIBM)

Noehammer, H. \& Byer, P. H. 1997. Effects on variables on participating in residential curbside recycling programs. Waste Management and Research 15, 405-427.

Nyamwange M. 1996. Public perceptions of strategies for participations in recycling programs Journal of Environmental Education 27 (4), 19-24.

Oskamp, S., Burkhardt, R. L. Schultz, P. W., Hurin, S., \& Zelezny, L, 1998. Predicting three dimensions of residential curbside recycling: Am observational study. Journal

Oskamp, S., Harrington, M. J., Edwards, T. C., \& Shewood, D. L. 1991. Factors influencing household recycling behavour. Environmental and Behavour 23 (1), 494 - 519.

Oskamp, S., Zelenzny, L., Schultz, P., Hurin, W., \& Burkhardt, R. 1996. Commingled verses separated curbside recycling: does sorting matter? Environment and behavour.28 (1), 73-91.

Perunding, 2001. Solid Waste Management in Malaysia: Overview and Information Paper, Danish Coopration in Environment and Development.

Polprasert, C. 1998. Organic waste recycling program. Thailand: Asian Institute of Technology.

Reschovsky, I. \& Stone, S. 1994. Market incentive for household waste recycling. Paying for what you throw away. Journal of policy analysis and management. 13 (1), 120-139.

Roberts, J. A. \& Bacon, D. R. 1997. Exploring the subtle relationships between environmental concern and ecologically conscious behavour. Journal of Business Research, 40.79-89, 1165.

Schultz, P., W., Oskamp, S., \& Mainieri. T. 1995. When recycles and when? A review of personal and situational factors. Journal of Environmental, Pyschology.15,105-121.

The $10^{\text {th }} \quad$ Malaysia Plan: http://www. $\quad$ epu. $\quad$ gov. my/html/themes/epu/html/RMKE10/rmke10_english. html10 June 2010

Van Houtven, G. \& Morris, E. 1999. Household behavour under alternative pay-as you throw Van Houtven, G. \& Morris, E. 1999.Household behavour under alternative pay-as you, 75 (4), 515-537.

Waite, R. 1995. Household Waste Recycling, London: Earthscan Publications Ltd. Waste Management and Research 12 ( 3), 257 - 270

Yahaya, N. 2007a. Solid waste management: Conference on climate change preparedness. National Solid Waste Department. Kuala Lumpur. 11 September.

Yahaya, N. 2007b.The New National Solid Waste Department. The New Sunday Time, 1 January

Yassin, S. M. 2006. Waste Management Conference, Ministry of Local Government and Housing Kuala Lumpur 16 May 2006

Yi, Y. ,Harloff, S. L. \& Meyer, P. B. 1999. Factors affecting household-level environmental decision making: A three county comparison of the determination of household recycling. UrbanEcosystem. 3, 149-168. 